\title{
Ueber die Flossenmuskeln des Seepferdchens (Hippocampus antiquorum) und über Muskelstructur im Allgemeinen. \\ Von
}

Alexander hollett.

Hierza Tafel VII und VIII.

Durch die eigenthümlichen Bewegungen, welche die Rückenflosse des Seepferdchens beim Schwimmen des Thieres macht, wurde Ranvier auf die Untersuchung der Muskeln dieser Flosse gefübrt. Die Flosse bewegt sich bekanntlich nicht als Ganzes wie bei anderen Fischen, sondern es lauten eine Reihe von Ausbiegungen nach beiden Seiten des Thieres wellenförmig mit grosser Geschwindigkeit iiber dieselbe ab.

Den Grund für diese eigentbümliche Art der Bewegung fand Ranvier in der Anordnung der Muskulatur der Flosse.

Diese ist in einem knöchernen Gehäuse enthalten, welches durch eine Längsscheidewand, die von den Gräten der Flosse gebildet wird, in zwei seitliche Hälften getheilt wird. $\mathrm{Zu}$ beiden Seiten der Scheidewand sind kleine conische Muskel angeordnet, welche jeder seine besondere Sehne hat. Man muss annebmen, dass diese isolirten Muskeln nicht simultan, sondern successive in Thätigkeit gerathen, woraus sich das Spiel der bewegten Flosse erklärt.

Ranvier fand nun aber auch an den Fasern dieser Flossenmuskeln, die er nach mehrstündiger Behandlung mit verdünnter Osmiumsäure (1:300) mikroskopisch untersuchte, einige bemerkenswerthe histologische Eigenthümlichkeiten. Die Fasern, welchen er einen mittleren Durchmesser von $50 \mu$ zuschreibt, besitzen ein von der quergestreiften Substanz des Muskels weit abstehendes Sarkolemma. Der Raum zwischen beiden $(5-10 \mu$ breit) ist ausgefullt von einer mit grossen Kernen durchsetzten körnigen Masse. Jede solche Faser besitzt wieder ibre besondere Sehne und die Sehnen einer Anzahl solcher Fasern vereinigen sich in besonderer Weise 
zar Sehne je eines der beschriebenen conischen Muskeln. Der Verbindung der einzelnen Faser mit ihrer Sehne wendet nun Ranvier seine grösste Aufmerksamkeit $\mathbf{z u}$, da ihm die beobachteten Details, wie das in der That auch der Fall ist, wichtig für die Frage des Zusammenhanges von Muskelfaser und Sehne erscheinen. In dieser Beziehung kommt Ranvier auf seine im Jahre 1874 tiber die betreffenden Muskeln publicirte Notiz auch wieder zurück in dem 4. Fascikel seines Traité technique d'histologie (pag. 508 a. 509 ) und in den Leçons d'anatomie générale sur le système musculaire (Paris 1880 pag. 241). In dem letzteren Werke finden sich auf Seite 222 und 242 zwei gleiche Abbildungen einer solchen Muskelfaser, von welchen die erstere aber auch noch zur Erläuterung gewisser Structurverhältnisse der Muskelfasern benutzt wird. Dabei nimmt Ranvier auch Bezug auf den in seinen Zcichnungen dargestellten optischen Querschnitt der Faser. An der Abbildung desselben sieht man das Sarkolemma eine körnige von Kernen durchsetzte Masse umfassen, in deren Mitte der Durchschnitt der quergestreiften Substanz in Form einer zwölftheiligen Rosette erscheint. Das von dem Contour der Rosette umfasste Areal ist schematisch mit geraden Strichen schraffirt.

Den Einkerbungen der Rosette entsprechend erseheint in der Seitenansicht der Faser eine Längsstreifung und diese soll nach Ravier den Zwischenräumen von Abtheilungen der Muskelsubstanz entsprechen, die Ranvier (vergleiche 1. c. p. 221), indem er einer unglücklich gewählten Bezeichnung Leydig's folgt, als "Muskelprimitivcylinder" bezeichnet. Diese Primitivcylinder sollen die quergestreifte Substanz der Faser zusammensetzen und zwar soll jedem einzelnen vorspringenden Blatt der Rosette des Querschnittes ein vorspringender Primitiveylinder entsprechen und dureb diese Anordnung der Primitivcylinder an der Peripherie die quergestreifte Substanz der Muskelfaser die Form einer cannelirten Säule erhalten.

Diese Darstellung Ranvier's ist nicht richtig. Hätte Ranvier sein Object genauer untersucht, so wäre er auf Eigenthümlichkeiten im Baue der Fasern der Flossenmuskeln gefübrt worden, die zu den sonderbarsten und merkwürdigsten gehören, auf welche man bisher gestossen ist.

Als ich die Untersuchung der Muskeln des Seepferdehens in Angriff nahm, dachte ich nicht daran, eine besondere histologische Ausbeute zu machen. Ich glaubte vielmehr, dass Ranvier hier 
schon alles Wesentliche gesehen bätte und batte physiologische Studien in Aussicht genommen. Es ist nämlich nicht bloss die früher erwähnte eigenthümliche Bewegungsart der Flossen bei der Beobachtung des Thieres auffallend, sondern auch das uberaus rasche Spiel der Flossen im Vergleich mit den trägen Bewegungen, welche z. B. die Muskeln des Schwanzes ausführen.

$\mathrm{Da}$ ich nun kurz zuvor verhältnisswässig schwierig zu untersuchende Muskeln von Arthropoden auf ihre physiologischen Eigenschaften (zeitlichen Verlauf dor Einzelzuckung, Erregbarkeit, Entstehung und Verlauf des Tetanus, Ermüdung u. s. w.) geprüft hatte $^{1}$ ), so glaubte ich, dass mir das auch bei den Muskeln des Seepferdchens gelingen werde. Allein weder mit graphischen, noch mit stroboscopischen Methoden liess sich etwas ausrichten, für die ersteren sind die Flossen zu zart, die letzteren scheitern, weil das Spiel der Flossen sofort aufhört, wenn man das im Wasser befindliche Thierchen, um es $z u$ fixiren, anfasst. Wird es gehalten, so macht es keine Bewegung, im Gegentheile, es erscheint wie hypnotisirt und vollständig regungslos. Wir bleiben also vorlaiufig auf die angeführten Wahrnehmungen der Bewegungen der Flossen des frei schwimmenden Thieres und des greifenden Schwanzes beschränkt, damit treffen aber ganz grossartige Verschiedenheiten des histologischen Baues der Flossenmuskeln und der ubrigen Skeletmuskeln des Thieres zusammen. Ich bemerke, dass ich mich erst, weil das bei Ranvier auch nicht zu finden war, davon überzeugte, dass die Analflosse und die Kiemenflossen von ganz ebenso gebauten Muskeln bewegt werden, wie die Rückenflosse, und dass diese Flossenmuskeln eben allesammt von den ganz anders gebauten ibbrigen Skeletmuskeln verschieden sind.

Ehe ich aber nun daran gehe, die merkwürdige Structur der Flossenmuskeln des Seepferdchens darzulegen, muss ich noch einige weitere einleitende Bemerkungen machen. Ich habe mich bei der Untersuchung derselben an jene Methoden gehalten, welche mich bei meinen Untersuchungen ${ }^{2}$ ) über den Bau der quergestreiften Muskelfasern zu einer in allen Theilen consequenten Darstellung des Baues derselben geführt haben, an dem ich, wie wir sehen

1) Denkschriften der math.-naturw. Klass. d. kais. Akad. zu Wien. Bd. LII, p. 194.

2) Denkschriften der math.-naturw. Klasse der kais. Akad. der Wissen- 
werden, trotz neuerer abweichender Darstellungen ${ }^{1}$ ) unerschittert festhalten muss.

Ja wir werden gerade in den Flossenmuskeln des Seepferdchens einen Prifstein jener Auffassung kennen lernen, wie er entscheidender gar nicht gedacht werden kann.

Ich habe in den bisher veröffentlichten Theilen meiner Untersuchungen des Baues der quergestreiften Muskelfasern zu erweisen gesucht, dass der vom Sarkolemma umschlossene Inhalt der quergestreiften Muskelfaser aus zwei wesentlich zu unterscheidenden Theilen besteht: aus dem Sarkoplasma und aus den Fibrillen. Die letzteren sind die Träger der Querstreifung. Sie sind gruppenweise zu strang- band- oder röhrenförmigen Bündeln zusammengeordnet und oft erscheinen auch noch diese Bündel (Muskelsäulchen) wieder zu grösseren Gruppen geordnet. Die Muskelsänlchen und die Muskelsäulchengruppen sind von dem Sarkoplasma auseinandergehalten.

Diese Zergliederung der Muskelfasern stiutzte ich auf eine grosse Zahl von Thatsachen der vergleichenden Histologie.

Und ich habe mit dem grössten Nachdrucke betont, dass für die sichere Begrindung einer richtigen Anschauungsweise des Muskelbaues gerade die Resultate ausgedehnter vergleichend histologischer Studien von der grössten Wichtigkeit sind.

Es zeigte sich nämlich in verschiedenen Fasern desselben Muskels und in den Muskelfasern verschiedenen Thiere eine ganz unerwartete Mannigfaltigkeit in der Anordnung der wesentlichen Theile einer Muskelfaser.

Durch alle diese Mannigfaltigkeiten hindurch fand ich aber

schaft. in Wien. Bd. XLIX, pag. 81 (I. Theil) u. Bd. LI pag. 23 (II. Theil). Ein III. Theil enthaltend: die mikroskopischen Vorgänge bei der Contraction und das Verbalten der Muskelfasern im polarisirten Lichte wird demnächst abgeschlossen und veröffentlicht werden. Hier werden wir uns grösstentheils nur auf die bereits veröffentlichten Theile zu beziehen haben.

1) Melland: A simplified view of the histology of the striped muscle-fibre. Quaterl. Journal. of microscop. science Vol. XXV, New. Ser. pag. 371, London 1885. Van Gehuchten: Étude sur la structure intime de la cellule musculaire striẻe. (Extrait de la Revue „La cellule“ t. II. 2. fascicul. Louvain, Gand et Lierre 1886); ferner: Anatomischen Anzeiger $1887 \mathrm{Nr}$. 26, pag. 792 . Macallum: On the nuclei of the striated muscle-fibre in Necturus lateralis. Quaterly Jourm. of microscop. scienc. Vol. XXVII New. Ser. pag. 461. London 1887. Marshall: Observat. on the struct. and distribut. of striped and unstriped muscle in animal Kingdom and a theory of muscular contract. Ibidem Vol. XXVIII pag. 75, Lourlon 1987. 
die Deutung, welche ich den wesentlichen Theilen der Muskelfaser gegeben hatte, bewährt. Wie ich auf Grund der Befunde an Alkoholpräparaten, an mit Säure oder mit Goldchlorid und Säure behandelten Muskelfasern, an Querschnitten also behandelter Muskelfasern, ferner an tingirten und imprägnirten gebärteten Muskelfasern und an Quersehnitten der letzteren, endlich an ganz firisch, noch lebend ohne irgend welchen Zusatz untersuchten Fasern und an Querschnitten von solchen za jener Deutung der wesentlichen Theile der Muskelfasern gelangte, habe ich in den erwähnten Abbandlungen ausführlich dargelegt und ich gab mich der Hoffnung lin, damit einer allgemeinen Verständigung über den Muskelbau die Wege geebnet zu haben. Damit sollte aber dem höchst unerfreulichen Zustande, in welchem sich die Histologie der quergestreiften Muskelfasern durch längere Zeit befand, ein Ende gemacht werden.

Es scheint nun nicht, dass ich den beabsichtigten Zweck erreicht habe.

Es ist mir darum erwünscht, dass ich mit der Darlegung des merkwürdigen Baues der Flossenmuskeln des Seepferdchens und mit einer daran geknüpften Kritik der früher erwähnten neueren Muskelarbeiten meine Bestrebungren fortsetzen kann.

Ich muss gestehen, dass ich, als ich zuerst Querschnitte gehärteter Flossenmuskeln ansah, zwar in grosses Erstaunen versetzt war, dass ich aber, was ich sah kaum verstand.

Ich vermuthete aber sofort, dass hier vergoldete Muskeln die erwünschte Aufklärung bringen raüssten und das war auch der Fall. Ich will darum auch hier die Goldbilder zuerst besprechen. An frisch vergoldeten Muskeln findet man bekanntlich immer das Sarkoplasma roth gefärbt, die Muskelsäulchen dagegen ungefärbbt ${ }^{1}$ ). Ich brachte dem lebenden Thiere entnommene Stückchen der Flossenmuskeln in das Goldbad ( $0,5 \%$ ige Lösung von Goldchlorid) und liess sie 5-10-15 Minuten in demselben, während ich sie mittelst Platinnadeln etwas auseinander zog. Dann brachte ich sie, nachdem das überschüssige Gold mittelst Filtrirpapiers möglichst abgesaugt war, in Bastian-Pritchard'sche Reductionsfluissigkeit. War die Reduction eingetreten, so wurde ein Stückchen der Muskeln auf den Objectträger gebracht, etwas Glycerin (2 Theile auf 1 Theil Wasser) hinzugesetzt und das Stückchen mittelst eines scharfen Scalpelles

1) Vergleiche meine Untersuchungen 1. c., I. Theil, pag. 121. 
quer dem Faserverlauf fein gehackt, um so Querschnitte der vergoldeten Fasern zu erhalten. Das gelingt auch gar nicht schwer. In jedem der so angefertigten Präparate finden sich in der Regel neben zahlreichen Längsansichten und Schrägschnitten von Muskelfasern immer auch eine Anzahl ron reinen Querschnitten. In Fig. 1 ist eine Reihe von solchen Querschnitten vergoldeter Muskelfasern dargestellt. Man sieht an denselben die Muskelsäulchenquerschnitte (Cohnheim'schen Felder) und das Sarkoplasma durch die Goldbehandlung auf das Schönste differencirt, die ersteren erscheinen weiss, das Sarkoplasma roth gefärbt, Fig. 1 a a. b.

Ueberraschend ist aber die relative Menge des Sarkoplasmas, die Form und Anordnung der Muskelsäulchenquersehnitte und die uberaus grosse Mannigfaltigkeit, welche in Bezug auf alle diese genannten Erscheinungen bei der Untersuchung der einzelnen Faserquerschnitte zu Tage tritt.

Wie unter den Menschen nicht zwei Individuen gefunden werden können, von welchen eines vollkommen dem anderen gleicht, so geht es auch hier, ja es kommen sogar sehr weitgehende individuelle Abweichungen der einzelnen Faserquerschnitte vor. Die immer wiederkehrende Ei genthümlichkeit der Flossenmuskeln des Seepferdehens im Vergleich mit anderen Muskeln ist aber Eine breite Wandschichte von Sarkoplasma unter dem Sarkolemma, in welcher Schichte die Kerne (in Fig. 1 a u. b leicht kenntlich) der Muskelfaser sich befinden und eine in versehieden gestaltete Gruppen zerstreute Anordnung der Muskelsäulchen, deren numerisches Verbältniss in Muskelquerschnitten von ganz nabe stehenden Durchmessern tuberdies ein sehr wechselndes ist.

Die Muskelsäulchen sind zu Gruppen geordnet, welche bandförmige und dabei wellenartig geschlungene, oder voluten-, oder c- oder $\varepsilon$ - oder kranzförmige, kreisrunde oder ovale und noch mannigfach andere Figuren auf dem Querschnitte darbieten. In diesen Gruppen haben aber auch die Muskelsäulchen selbst sehr vielfach in Bezug auf Form und Grösse abweichende Querschnitte, im Allgemeinen herrschen aber Muskelsäulchen von länglichem Querschnitte vor.

In den Figuren 1 u. 2 sind möglichst viele dieser Mannigfaltigkeiten dargestellt. In Figur $1 \mathrm{a}$ u. $\mathrm{b}$ und in Figur 2 ist die Darstellung der Querschnitte völlig ansgeftuhrt, in Fig. 1 c, d, e, f sind nur die Muskelsäulchengruppen mittelst einfacher Contouren 
eingezeichnet. Der stark vergrösserte Querschnitt Fig. 2 zeigte besonders schön eine ganze Reibe der verschiedensten Formen der Querschnitte der Muskelsäulchen und der Muskelsäulchengruppen und wurde darum für die Darstellung ausgewällt. Ich glaube durch den Hinweis auf diese Figuren weiterer Darlegungen enthoben zu sein, die bei der unbegrenzten Mannigfaltigkeit der Verhältnisse in den einzelnen Fasern niemals erschöpfend sein könnten. Das Sarkoplasma erscheint an den vergoldeten Muskeln fein granulirt, die Kerne sind nicht wesentlich tiefer gefärbt als das Sarkoplasma, aber meist von einem feinen Contour scharf umgrenzt. Durch die Spärlichkeit ron in ihrem Innern vorhandenen einzelnen Körnehen erscheinen sie glatt im Vergleich mit dem Sarkoplasma und oft tritt ein Nucleolus, oft ein grösserer centraler dunkler Fleck mit grosser Deutlichkeit in denselben hervor - (siehe die leicht kenntlichen Kerne in den Randschichten von Fig. 1 a u. b, Fig. 2 u. Fig. 6). Dieses Ansehen der Kerne ist von dem, welches man sonst in vergoldeten Muskeln bei Vertebraten sowohl, wie bei Arthropoden gewöhnlich findet, versehieden. Die Kerne sind meist tiefer mit Gold gefärbt, als das Sarkoplasma und ihre Substanz von verklumpten Balken und Körnern, die dann am tiefsten gefärbt erscheinen, erfüllt.

Ich will nun an die gegebene Darstellung der Querschnitte vergoldeter Flossenmuskeln des Seepferdchens sogleich einige vergleichend bistologische Betrachtungen anschliessen.

Wenn wir uns fragen, ob bei anderen untersuchten quergestreiften Muskelfasern Anordnungen von Sarkoplasma und Muskelsäulchen bekannt geworden sind, welche sich in irgend einer Weise der so ganz besonderen Anordnung in den Flossenmuskeln des Seepferdchens annähern, so glaube ich diese Frage allerdings bejahen zu können.

Bei den Vertebraten zwar ist, so viel ich weiss, ein solcher Fall noch nicht beobachtet worden. Dagegen gibt es bei einzelnen Evertebraten quergestreifte Muskelfasern, welche gewisse Aehnlichkeiten ibres Baues mit dem der Flossenmuskeln des Seepferdchens zeigen.

Ich führe hier vor Allem die Muskeln der Fliegen an (Musca domestica, vomitoria und Sarcophaga carnaria), welche ich im II. Theile meiner Untersuchungen ${ }^{1}$ ) ausführlich beschrieben habe.

1) 1. c. Bd. II, p. 37 . 
Da am angeführten Orte kein Goldbild ron Fliegenmuskeln sich dargestellt findet, so füge ich hier zum unmittelbaren Vergleiche in Fig. 3 ein solches bei. Die Cohnheim'schen Felder des Querschnittes der Fliegenmuskeln sind verlängert, mit ihrem langen Durchmesser annäbernd radiär gestellt. Ganz besonders ausgezeichnet sind aber die Fliegenmuskeln durch die gruppenweise Anordnung der Cohnheim'schen Felder, die Gruppen bilden gürtelförmige Reihen. Die Gürtel umschliessen centrales, die Kerne enthaltendes Sarkoplasma oder es tritt um diesen innereu Gürtel und von diesem durch eine ebenfalls gürtelförmige Lage von Sarkoplasma getrennt ein zweiter äusserer Gürtel auf (vergl. Fig. 3). In bestimmten Fasern kommt, von diesem zweiten Gürtel wieder durch Sarkoplasma gretrennt, noch ein die beiden anderen Gürtel umfassender dritter Gürtel vor, endlich manchmal auch noch ein vierter.

Der innerste Gürtel weicht in seiner Form von den äusseren Gürteln gewöhnlich etwas stärker ab und setzt sich aus zwei, drei oder vier sectorenartig angeordneten und sehr verschieden gestalteten Gruppen von Muskelsäulchen zusammen (vgl. wieder Fig. 3). Die Grenze der einzelnen Gürtelreihen und die Dicke der Gürtel ist eine sehr wechselnde. In den Figuren $11 \mathrm{~A}$ und $12 \mathrm{a}, \mathrm{b}, \mathrm{c}, \mathrm{d}$, $e, f, g, T a f$. II der erwähnten Abhandlung finden sich eine Reihe der ùberaus mannigfaltigen Querschnittsbilder von gebürteten Muskelfasern der Fliegen dargestellt, welche diese Verbältnisse veranschaulichen. Querschnitte vergoldeter Fliegenmuskeln zeigen dieselben auf das Schönste.

Die radiär gestellten verlängerten Cohnheim'schen Felder erscheinen ungefärbt, das Sarkoplasma zwischen denselben und das Sarkoplasma zwischen den Gruppen und Reihen der Cohnheim'schen Felder dagegen von Gold roth gefärbt. Der Querschnitt Fig. 3 rührt von einer zweigürteligen Faser her, in deren centralem Sarkoplasma eine Kernreihe sich fand. Der auf dem Querschnitte sichtbare Kern liegt in der Mitte desselben.

In anderer Weise als die Fliegenmuskeln mit ihren gürtelfồrmigen Reihen und Gruppen von Muskelsäulchen nähern sich die Muskelfasern von Krebsen denen der Flossenmuskeln des Seepferdchens an. Ich beziehe mich dabei auf die in meinen Untersuchungen ${ }^{1}$ )

1) l. c. p. 42 . 
angefuhrten Krebse (Astacus fluviatilis, Homarus vulgaris, Maja squinado, eine Palaemon-Art), und muss bemerken, dass bei den Krustern, wie einer Mittheilung Köbler's') zu entnehmen ist, sehr wechselnde Verhältnisse und sehr mannigfache Anordnungen von Muskelsäulchen، und Sarkoplasma zu finden sein werden. Anch bei den angefïhrten Krebsen, welche ich untersuchte, ist das Bild des Muskelquerschnittes selbst bei den Muskelfasern derselben Species ein sehr wechselndes. Im Allgeweinen babe ich aber das folgende hervorgehoben ${ }^{2}$ ), was ich hier wieder durch die Abbildung eines Goldbildes erläutern will. Fig. 4 stellt ein Stück eines Querschnittes einer vergoldeten Muskelfaser von Maja squinado dar. Unter dem Sarkolemma befindet sich eine verhältnissmässig dicke Lage von Sarkoplasma, von dieser gehen mittelst conischer Ansätze eine beschriinkte Anzabl von Sarkoplasmabalken aus, welche theils zu einem netzartigen Geäder zusammentreten, theils sich baumförmig in die gleich zu erwähnenden kleineren Balken auflösen. Durch diese starken Balken erscheint der ganze Querschnitt in eine Anzahl von grossen Feldern getheilt. Von dem Sarkoplasma an der Oberfläche und von den starken Balken entspringen wieder mit conischen Ansützen kleinere Sarkoplasmabalken, die wieder theils zu einem netzartigen Geider zusarnmentreten, theils baumförmig sich in kleinerc Balken auflösen und die grossen Felder mehr weniger vollkommen in eine Anzahl kleinerer Felder abtheilen. Endlich entspringen sowobl von dem Sarkoplasma an der Oberfläche, als auch von den erwähnten stärkeren und schwächeren Balken wieder kleinere zu einem Geäder zusammentretende Balken und oft von diesen in ähnlicher Weise noch feinere Balken, welche endlich die kleinsten Felder (Cohnh e im 'sche Felder) umgeben. Die Kerne dieser Fasern befinden sich zerstreut in dem Sarkoplasma an der Oberfläche und in denstarken Balken.

Die Muskeln der Krebse zeigen also bauptsächlich nur in Bezug auf die starken Ansammlungen von Sarkoplasma eine Aehnlichkeit mit den Flossenmuskeln des Seepferdchens. Ferner erscheinen auch bei den Muskeln der Krebse die Cohnheim'schen Felder zu Gruppen geordnet. Die letzteren sind aber wieder zu Gruppen höherer Ordnungen vereinigt. Alle diese Gruppen er-

1) Compt. rend. T. CIV, pag. 592.

2) 1. c. 
scheinen in Form von mehr ebenmässig entwickelten rundlichen, drei-, vier- oder vieleckigen Feldern. Der Hinweis auf die Krebsmuskeln möge uns nun auch noch zu einer Betrachtung anderer Art Veranlassung geben.

Dächten wir uns auf dem ganzen Muskelquerschnitte nur Sarkoplasmabalken von der Stärke der feinsten in ähnlicher Anordnung, wie diese (Fig. 4) vorhanden, oder was dasselbe wäre eines der Felder vorletzter Ordnung auf den ganzen Quersehnitt ausgedebnt, so würden wir damit die Art und Weise versinnlicht baben, wie die Cohnbeim'schen Felder und das sie trennende Sarkoplasma an den Vertebraten-Muskeln gewöhnlich in die Erscheinung treten. Solche Muskeln stellen auch alle Muskeln des Seepferdchens dar, welche nicht für die Bewegung der Flossen dienen. In Fig. 5 sind das durch Gold gefärbte feine Sarkoplasmageäder und die von demselben abgegrenzten Cohnheim'schen Felder des Querschnittes einer gewöhnlichen quergestreiften Muskelfaser des Seepferdchens dargestellt.

Die Cohnheim'schen Felder erscheinen viel- meist fünfeckig; dort, wo die Adern des Sarkoplasma zusammentreffen, finden sich knotenartige Verdickungen vor und an einzelnen Stellen erscheinen diese Verdickungen zu grösseren sternförmigen Anschwellungen des Geäders erweitert. An dem abgebildeten Querschnitte sind zwei Kerne an der Oberfläche der Faser sichtbar. Wie ein Vergleich der Flossenmuskeln des Seepferdchens (Fig. 1 u. 2) und der gewölnlichen Muskeln desselben Thieres (Fig. 5) zeigt, ergiebt sich hier für ein Wirbelthier der Fall einer sehr weit gehenden Verschiedenheit in der Anordnung des Sarkoplasmas und der Form der Cohn heim'schen Felder (Querschnitte der Muskelsäulchen) in functionell verschiedenen Muskelfasern desselben Thieres.

Bisher waren morphologische Verschiedenheiten dieser Art nur bei den Artbropoden bekannt. Man erinnere sich an die Querschnittsbilder der Muskelfasern von Hydrophiliden, Dyticiden und von anderen Coleopterenfamilien, von Hymenopteren, von Fliegen und von Krebsen, von welchen letzteren früher schon auf einige Beispiele hingewiesen warde and welche Arthropodenmuskeln sich in meinen Untersuchungen (I. u. II. Theil) ${ }^{1}$ ) ausfihrlich beschrieben und zam Theile anch abgebildet finden.

1) I. c. 
Ehe wir nun die Goldbilder verlassen, die wir bisher nur auf dem Querschnitte von Muskelfasern betrachtet baben, muss ich auch die Längenansicht der vergoldeten Flossenmuskeln des Seepferdchens behandeln.

Optische Längsschnitte vergoldeter Flossenmuskeln kann man neben den Querschnitten in überwiegender Menge in Präparaten beobachten, die so hergestellt wurden, wie das früher angeführt warde.

Man erhält von denselben ebenso mannigfach wechselnde Bilder, wie das von den Querschnitten angeführt wurde, was nach der Kenntnissnahme der auf den Querschnitten sichtbaren Dinge auch sofort völlig verständlich ist. So wie auf den Querschnitten kehren aber auch auf den Längsschnitten trotz allen Mannigfaltigkeiten die wesentlichen Theile des Bildes immer wieder. Fig. 6 stellt einen Längsschnitt durch eine Flossenmuskelfaser vom Seepferdchen bei derselben Vergrösserung dar, wie sie in dem Querschnitte Fig. 2 vorliegt. Es prïsentirt sich die breite, die Kerne enthaltende Sarkoplasmalage (Fig. $6 \mathrm{~S}_{1}$ ), unter dem Sarkolemma (Fig. 6 Sl). Im Innern der Fasern fallt eine durch breite rothe bandartige Streifen bedingte grobe Längsstreifung zunächst auf. In Fig. 6 erscheinen zwei solche breite Streifen $\left(S_{2}, S_{2}\right)$. Die Zahl derselben auf verschiedenen optischen Längsschnitten verschiedener Muskelfasern ist aber oft eine viel grössere und die Breite dieser Streifen eine sehr wechselnde. Die Streifen gewähren bei bestimmter Einstellung den Eindruck, dass sie sich allmählich in die Tiefe verlieren und beim Wecbsel der Einstellung hat man den Eindruck, dass sie von Blättern herrühren, welche leicht gebogen durch die Substanz der Faser laufen. Es entsprechen diese Streifen den breiten in den optischen Längsschnitt fallendèn, die Muskelsäulchengruppén von einander trennenden Sarkoplasmalagen.

Dort, wo solche Muskelsäulchengruppen selbst in den optischen Längsschnitt fallen, erscheinen die Bilder M, M, M, Fig. 6. Die Querreihen von Knoten in denselben entsprechen den zwischen den Gliedern $Z$ der Muskelsäulchen an mit Säure oder mit Goldchlorid und Säure behandelten Muskelfasern auftretenden Knotenreihen I (siehe meine Untersuchungen etc. I. Theil l. c. pag. 170 u. d. f.).

Dort findet sich auch eine Erklärung der Querreihen der Knoten und der die Knoten der Querreihen wieder zu regelmässigen Längsreihen verbindenden Streifen. 
Beide sind der optische Ausdruck der Sarkoplasmadurchgänge zwischen den einzelnen Muskelsäulchen. Ich labe dort auch angeführt, dass man sich das Sarkoplasma um die Muskelsïulchen ähnlich angeordnet vorstellen müsse, wie das Wachs um die Zellen einer Honigwabe.

Stellen wir uns eine solche Anordnung in der ganzen Länge einer Muskelfaser vor, so wtirden wir von Serienschnitten, die senkrecht auf die Axe angelegt würden, immer dasselbe Bild erbalten, wenn die Dicke der Wände und die Durchmesser der Lumina des Zellenwerkes immer dieselben bleiben wirden.

Auf einem optischen Längsschnitte würden wir aber dann in Form von gleich breiten und gleich weit abstehenden Längsstreifen die optischen Durchschnitte der Wände des Zellenwerkes sehen und die Abstände der Streifen wärden den optischen Durchsehnitten der Lumina des Zellenwerkes beziehungsweise der diese Lumina ausfiullenden Substanz entsprechen. Stellen wir uns aber nun die Wände in regelmässigen Abständen abwechselnd verdickt und wieder verdunnt vor und die Durchmesser der Lumina des Zellenwerkes das eine Mal entsprechend klein, das andere Mal entsprechend gross, dann wiirden abwechselnd sich Quersebnitte ergeben, auf welchen dickere Balken kleinere Maschenrïume oder dünnere Balken grössere Maschenräume umfassen wïrden; und auf optischen Lü̈ngsschnitten würden, als mit Knoten besetzte Streifen, die optischen Längsschnitte der Wände und, als mit Bäuchen und Einziehungen versebene Streifen, die Lumina des Zellenwerkes beziehungsweise die diese Lnmina ausfüllende Substanz erscheinen.

Diese stereometrische Vorstellung von dem Sarkoplasma und den Muskelsäulchen vergoldeter Muskelfasern babe ich am angeführten Orte ausfübrlich zu begrinden gesucht und sie wird, wenn wir einmal festhalten, dass das, was am vergoldeten Muskel ungefärbt erscheint, die Muskelsäulchen sind; dagegen das, was durch Gold roth gefärbt erscheint, das Sarkoplasna ist, durch unsere Fig. 6 für den Flossenmuskel des Seepferdchens unmittelbar veranschaulicht.

Der Grund für die mit Einziehnngen regelmässig abwechselnden Bäuche der Muskelsänlchen des vergoldeten Muskels ist die Wirkung, welche Süuren auf die regelmässig wechselnden Streifen $\mathrm{Q}$ (Bowman-Brücke'schen Streifen) und Z (Amici-Krauseschen Streifen) der Muskelsäulchen ausïben; die $Q$ quellen in 
Säuren viel rascher und stärker auf, als die $Z$ und diese durch die verschiedene Quellbarkeit der $Q$ und $Z$ bedingte Form der Muskelsäulchen ist wieder die Ursache der besonderen Form der zwischen den Muskelsäulchen vorhandenen Sarkoplasmawände.

Auch diese Erklärung der Erscheinungen an mit Säuren oder mit Goldchlorid und Säuren behandelten Muskelfasern findet sich in den angeführten Untersuchungen (1. c.) ausfibrlich entwickelt.

Andere Autoren sind, wie wir sehen werden, mit den der Länge und Quere nach verbundenen Knotenreihen in der Längenansicht vergoldeten Muskelfasern allerdings viel schneller fertig geworden als ich, indem sie einfach ein der Länge und Quere nach entwickeltes Fadennetz, welches in den Knotenpunkten Anschwellungen besitzt, zu sehen meinten. Ein solches Fadennetz existirt in der Muskelfaser nicht, nur der Schein eines solchen ist vorhanden. Ich halte meine Erklärung des scheinbaren Fadennetzes für die allein richtige und möchte sehr empfehlen, dass man sie prife und sich mit ibr vertraut mache; gerade meine Erklärung der Säure- und Goldsäurebilder scheint mir ein wichtiger Punkt für eine allseitige Verständigung über den Bau der quergestreiften Muskelfasern zu sein.

Es handelt sich aber jetzt vorerst noch darum, den Bau der Flossenmuskelfasern des Seepferdchens auch noch mittelst anderer Methoden klar zu legen. Ich will zu dem Ende zunächst mit den Querschnitten der vergoldeten Fasern die Querschnitte von in Alkohol gehärteten Flossenmuskeln vergleichen. Stücke von Flossenmuskeln, die Thieren entnommen wurden, die längere Zeit in $93 \%$ Alkohol lagen, wurden in Celloidin eingebettet und in der Weise weiter verarbeitet, wie ich es in den Untersuchungen (II. Theil l. c. p. 25) beschrieben habe.

Die erhaltenen Schnitte wurden in sehr verdtinnte Hämatoxy. linlüsung von Renaut (I. Theil l. c. p. 97) gebracht, nach der Tinction in starkem Alkohol entwässert, mit Origanumöl durchsichtig gemacht und in einer Lösung von Dammarharz in Xylol eingeschlossen. Ist die Differenzirung gut gelungen und das hängt, wie man sich bald ïberzeugen wird, von der leicht auszuprobirenden Zeit des Aufenthaltes in der Ḧ̈matoxylinlösung ab, so erhält man Bilder, wie ich sie in Fig. 7 dargestellt babe.

Die Muskelsäulchendurchsehnitte (Cobnheim'sche Felder) erscheinen tief blau gefürbt, das Sarkoplasma dagegen hat nur 
eine schwach blaue Färbung angenommen, nur die Körnchen in demselben erscheinen dunkler blau gefärbt, in der Wandschichte des Sarkoplasma erscheinen die Kerne, eingefasst von einem tiefer blauen Contour, in der Mitte derselben ein Kernkörperchen. Die Form der Querschnitte der Muskelsäulchen und der Muskelsaulchengruppen erscheinen ganz analog wie bei den Goldbildern, nur sind sie in ihren Dimensionen ebenso, wie der ganze Querschnitt der Faser im Vergleich mit den Dimensionen der betreffenden Gebilde an den vergoldeten Muskelfasern bei derselben Vergrösserung sebr reducirt (vergl. Fig. 1 a a. b und Fig. 7).

Was wir also an den Querschnitten von vergoldeten Muskelfasern erfahren haben, bestïtigt sich auch auf den Querschnitten gehärteter und tingirter Fasern.

Kurz die Vergleichung der nach den angeführten verschiedenen Methoden erhaltenen Querschnitte der Flossenmuskelfasern führt uns zu demselben Resultate, welches ich bei der Vergleichung der Querschnitte vergoldeter und gehärteter Arthropodenmuskeln immer erlielt. Die mit Hämatoxylin stark gefärbten Cohnheimschen Felder der gehärteten Muskeln entsprechen den im vergoldeten Muskel weiss gebliebenen Feldern, die nicht oder nur schwach tingirte Substanz um and zwischen den Cobn beim'schen Feldern des Querschnittes gehärteter Muskelfasern entspricht den durch Gold roth gefärbten Theilen des Querschnittes vergoldeter Muskelfasern (Entersuchung. I. u. II. Theil 1. c. pag. 110 u. pag. 24).

Die Längenansicht von in der beschriebenen Weise tingirten, gehärteten Flossenmuskeln des Seepferdchens ist ebenfalls mutatis mutandis in Uebereinstimmung mit der Längenansicht der Goldbilder. Die Randschicht, entsprechend $\mathrm{S}_{1} \mathrm{~S}_{1}$ Fig. 6, erscheint nur schwach tingirt, und ebenso die breiten Sarkoplasmadurchgänge entsprechend $\mathrm{S}_{2} \mathrm{~S}_{2}$ Fig. 6, die Muskelsäulchengruppen, entsprechend M, M, M Fig. 6 erscheinen dagegen tief blau gefärbt und dadurch tritt an der tingirten Muskelfaser ebenso, wie an der vergoldeten eine grobe Längsstreifung neben der den Durchgängen zwischen den Muskelsäulchen entsprechenden feinen Längsstreifung in die Erscheinung.

So wie ich friber in vergleichend histologischer Beziehung dem Goldbilde der Flossenmuskel-Querschnitte das Goldbild eines Fliegenmuskel-Querschnittes an die Seite gestellt habe, so möge das jetzt auch mit den Hämatoxylinbilderu geschehen. Fig. 8 ist 
ein mit Hämatoxylin gefärbter Querschnitt einer gehärteten Fliegenmuskelfaser bei derselben Vergrösserung wie das Goldbild Fig. 3 . Es möge diese Gegenüberstellung ebenso zur Erläuterung der oben über die Arthropodenmuskeln gemachten Angaben, wie zum Erweise der schon mittelst der Goldbilder dargelegten morphologischen Aehnlichkeiten der Flossenmuskeln des Seepferdchens und der Fliegenmuskeln dienen.

In Fig. 8 erscheinen die radiär gestellten Cohnheim'schen Felder des Querschnittes tief blau gefärbt, das Sarkoplasma ist ungefärbt, nur die Körnchen in demselben erscheinen gefärbt. Die Cohnheim'schen Felder sind in zwei gürtelförmigen Reihen um das zwei Kerne aufweisende centrale Sarkoplasma gruppirt. Der innere Gürtel zerfällt noch tiberdies in vier sectorenartige Gruppen.

Es erübrigt uns jetzt noch zu besprechen, ob die an vergoldeten und eben so an gehärteten Flossenmuskeln des Seepferdchens wahrnehmbare Anordnung der Muskelsäulchen und des Sarkoplasmas auch an ganz frischen Muskeln zu sehen ist.

Bei einigem Bemühen gelingt es, an kleinen Stiickchen, die man mittelst einer Scheere aus einem Flossenmuskel herausgeschnitten und ohne allen Zusatz mit einem aufgedrikckten Deckgläschen auf einem Objectträger ausgebreitet hat, Querschnitte frischer Flossenmuskelfasern zu sehen.

Man sieht an denselben sofort eine Abgrenzung der breiten Randschicht des Sarkoplasmas von einer davon verschiedenen inneren Parthie der Muskelfaser angedeutet und hat dann auch mehr oder weniger deutlich den Eindruck, als ob die breite Randschicht eine, wenn auch nicht so regelmässige Rosette, wie sie $R$ a $n$ v i e r zeichnet, sondern eine mit unregelmässigen und verschieden grossen Buchten und Vorsprüngen versehene Rosette umfassen würde. Das Innere dieser Rosette erscheint nicht gleichförmig gezeichnet, sondern aus helleren und dunkleren Parthien zusammengesetzt, die wie unregelmässige und verschieden grosse, nur andeutungsweise abgegrenzte Flecken neben einander zu liegen scheinen.

Es bedarf einer hingebenden and aufmerksamen Betrachtung und wiederholten Durchmusterung des Bildes, um sich zu überzeugen, dass die dunkleren Parthien in ihrer Beschaffenheit mit jenen der breiten Randschichte übereinstimmen. Sie erscheinen wie die letztern leicht körnig getrübt, während die helleren Flecken glatt erscheinen. 
Hat man sich einmal über diese Verhältnisse in der erwähnten Weise belehrt, dann ist es nicht mehr schwer in den belleren Flecken die verschiedenartig gestalteten Muskelsäulchengruppen des Querschnittes zu erkennen, welche wir an Gold- und Hämatoxylinpräparaten kennen gelernt haben. Dass die Deutung, welche man dem Bilde des Querschnittes der frischen Faser also gegeben bat, die richtige ist, wird dann am Besten dadurch erhärtet, dass man, während das Auge des Beobachters auf dem Präparate rubt, $1 \%$ ige Ueberosmiumsäurelösung zwischen Objectträger und Deckgläschen eindringen lässt. Durch die Wirkung dieses Reagenz, dessen sich, wie angeführt, auch Ranvier für die Muskeln der Rückenflosse bediente, werden die Grenzen zwischen den glatt erscheinenden Muskelsäiulchengruppen und dem Sarkoplasma verdeutlicht und beide dadurch besser differencirt, dass sich das Sarkoplasma noch mehr verdunkelt und dessen Körnung viel deutlicher hervortritt. Zugleich werden auch die Kerne der Wandschichte dadurch deutlich. Ein Querschnitt, wie er sich nach kurzer Einwirkung der Ueberosmiumsiure und Verdrängung derselben durch Glycerin auf einem auf diese Weise erhaltenen Dauerpräparate präsentirte, ist in Fig. 9 dargestellt und nach den gegebenen Ausein andersetzungen ohne weitere Erklïrung verständlich.

Bei länger dauernder Wirkung der in der beschriebenen Weise applicirten Ueberosmiumsäure tritt häufig noch ein anderes belehrendes Bild auf.

Die Muskelsäulchengruppen umgeben sich mit hellen Säumen und man bat den Eindruck, als ob sie sich durch Schrumpfung von dem Sarkoplasma etwas zurïckgezogen hätten. In diesem Falle kann man sich bei flüchtiger Betrachtung besonders an Fasern mit reichlicheren, kleineren Gruppen (vergleiche Fig. If) zu der Annahme verleitet sehen, dass das von der Wandschicht umfasste Innere durch ein helles Geäder in verschieden gestaltete, aber das Innere gleichmässig erfüllende Felder zerlegt würde. Eine sorgfältige Betrachtung deckt aber die wahren Verhältnisse: die inselförmigen Muskelsäulchengrappen und die confluirenden Sarkoplasmamassen sofort anf und bei starken Vergrösserungen und günstiger Beleuchtung siebt man durch die die Muskelsiiulchengruppen und das Sarkoplasma trennenden hellen Säume noch zarte Bälkchen laufen und in die feinen, die einzelnen Muskelsäulchen einer Gruppe trennenden Sarkoplasmabalken übergehen. 
Ich habe ganz frische Muskelfasern der Flossenmuskeln des Seepferdehens auch im polarisirten Lichte und zwar aut Gypsgrund Roth I. Ordnung zwischen gekreuzten Nikolschen Prismen uutersucht und will auch dieser Untersuchung hier Erwähnung thun, weil ihr Ergebniss in vollem Einklange steht mit den nach anderen Methoden gemachten Befunden und sie zur Controlle derselben nicht veruachlässigt werden sollten.

Vor allem fällt an den einzelnen Fasern die Abwechslung von breiten Längsstreifen, in welchen die Farbe des Grundes nicht oder nur wenig geändert scheint, mit solchen auf, in welchen lebhafte höhere oder niedere Interferenzfarben je nach der Orientirung der Fasern auf der Gypsplatte zu beobachten sind. Die ersteren Streifen entsprechen den Randschichten des Sarkoplasna und den Sarkoplasmadurebgängen (zur Orientirung vergleiche nnan $S_{1} S_{1}$ und $S_{2} S_{2}$ Fig. 6). In denselben ist keinerlei Querstreifung zu sehen. Dic letzteren Streifen entsprechen den Muskelsïulchengruppen (zur Orientirung veryleiche man Fig. 6 M, M, M,). In der ausgezeichneten Querstreifung derselben weehseln einfach und doppelt lichtbrechende Abschnitte in der gewölunlichen Weise mit einander ab. In der Additionslage wie gewöhnlich Blau II. Ordnung mit Roth I. Ordnung, in der Subtractionslage Gelb I. Ordnung mit Roth I. Ordnung. Mit der grössten Schïrffe tritt schon bei mittleren Vergrösserungen in diesen Abschnitten die den feinen Sarkoplasmadurchgängen zwischen den einzelnen Muskelsüulchen der Gruppe entsprechende feine Längsstreifung als ungeänderte Grundfarbe hervor.

In den den breiten Sarkoplasmadurchgängen (zur Orientirung vergleiche $\mathrm{S}_{2} \mathrm{~S}_{2}$ Fig. 6) entsprechenden Streifen beobachtet man aber bei bestimmter Einstellung auch häufig, den ganzen Streifen oder einen Theil desselben einnehmend, Aenderungen der Grundfarbe, die als gleichmässig mit verwaschener gestiegener oder gesunkener Farbe bedeckte Flecken erscheinen. In diesem Falle gelingt es immer leicht durch Veränderung der Einstellung diese Flecken in das deutliche Bild der Muskelsäulchengruppen im polarisirten Lichte überzuführen und sich zu überzengen, dass die Flecken von nicht in die Einstellebene fallenden sondern darunteroder darüberliegenden Muskelsäulchengruppen herrührten. Nur wenn eine Muskelfaser zufällig so orientirt ist, dass das Licht, welches sie durchdringt nur Sarkoplasma durchsetzt, erscheinen breite Längsstreifen, welche bei allen Einstellungen nur die Farbe 
des Grundes zeigen, das letztere ist bei einer grösseren Anzahl von Beobachtungen gar nicht selten zu sehen.

Ebenso verhalten sich die den Randschichten (zur Orientirung vergl. Fig. $6 \mathrm{~S}_{1} \mathrm{~S}_{1}$ ) entsprechenden Streifen bei allen Einstellungen als einfach lichtbrechend. Diese Befunde bestïtigen nur, was man über das Verhalten des Sarkoplasmas und der Muskelsäulchen bei den quergestreiften Muskelfasern ganz allgemein erfahren hat und sind, wie gesagt, nur als Ergänzung der trüheren Befunde an den Flossenmuskelfasern von Werth.

Ieh will nun nach der Darstellung des Banes der Flossenmuskeln des Seepferdchens, die sich völlig der Darstellung des Muskelbaues anschliesst, die ich in sleu erwilinten Untersuchungen zu geben mich bemültte, einige kritische Blicke anf die friher erwïhnten neueren Muskelarbeiten werfen.

Wir werden damit einige Blithen jener romantischen Histologie kennen lernen, die sich gerade die quergestreiften Muskelfasern als ein ganz bevorzugtes Object ansgewiillt hat.

In der Muskelromantik ist in der That Erstamliehes geleistet worden.

Schon im Jahre 1872 bemerkte du Bo is -Reymond gelegentlich mit feiner Satyre, dass kaum zwei ristologen sich finden möchten, die ther den Bau der Sehne mit einander einig sind, und kaum einer der üher den Ban des Muskels mit sich selber einig ist. Wer möchte sich viel wundern, wenn heute ein nener Kritiker sich abermals so vernebmen liesse.

Diesen Zustand der Muskelhistologie hat aber nach meiner Ueberzeugung weit weniger die Schwierigkeit des Objeetes selhst, sondern vielmehr die Ueberproduction phantastischer Auslegungen, mit welchen es bedacht wurde, verschuldet. Ein rnhiges, streng analytisches, auf die Beobachtung möglichst zahlreicher, den verschiedensten Thieren entnommener Oljecte gegrindetes Verfahren, welches sorgsam auf die Verknüpfung älterer und neuerer Erfahrungen bedacht gewesen wäre, wurde den complicirten Erscheinungen des Muskelbaues gegenüber weit weniger oft in Anwendung gebracht, als die zusammenhanglose Ausdeutung einzelner Befunde, die sich nach dieser oder jener bestimmten Methode ergaben. So ist die aussergewöhnlich umfangreiche Literatur ïber diesen Gegenstand entstanden, in welcher sich die widersprechendsten Ansichten 
niedergelegt finden. Und damit ist, wie ich schon an einem anderen Orte bemerkte auch das Misstrauen gegen richtig erkannte Thatsachen gewachsen und der Verwirrung und Unentschiedenheit Thür und Thor geöffnet worden. Oder lässt es sich bestreiten, dass kaum ein anderer Gegenstand existirt, dem selbst viele Fachleute so urtheilslos gegenüberstehen, wie dem Bau der quergestreiften Muskelfasern. Die abenteuerlichsten Ansichten können vorgelegt werden, ohne dass sie gleich von vornherein mit Kopfschuitteln abgewiesen werden; nein sie werden neuen Ergebnissen streng methodischer Erweiterung unserer Kenntnisse oft ganz gleich gehalten und wie diese mit eben so viel Beachtung oder eben so viel Missachtung nur als Neuigkeiten im Wandel der Anschaungen hingenommen. Jabresberichte und Referate in Zeitschriften fördern aber unter der Devise: Keine Kritik! Nur objective Berichterstattung! diesen Zustand auf das Trefflichste, und er tritt uns auch an Orten entgegen, wo man im Gegentheile strengste Kritik absolut fordern sollte und misste, in Lehr- und Handbüchern, die im Capitel: Muskel nur cin buntes Allerlei aufgetauch ter Meinungen neben einandersteilon.

Hier wie dort sollte man endlich doch anfangen, mit mehr Bedacht vorzugehen.

Keine Kritik! kann doch unmögrlich bedeuten, dass uiber Alles, was veröffentlicht wird, auch wenn es den Stempel des Aberwitzes an der Stirne trägt, in ernsthafter Weise referirt werden muss. Wiirde z. B. der "anatomische Anzeiger" ein mit Abbildungen ausgestattetes Referat bringen, wenn heute einer käme, der behaupten wïrde, dass das Gehirn nicht, wie man bisher geglaubt, in der Schädelhöhle sich befindet sondern vielmehr in der Brustböhle und dass in der Schädelhöhle die Lungen sich befinden?

Gewiss nicht!

Kommt aber jemand der über die Histologie der Muskelfasern Lehren vorbringt, die - ich sage nicht zu viel - ungefähr dieselbe Bedeutung haben, wie das fingirte Beispiel aus der Anatomie, dann erfïllen in der Regel ansführliche Referate darüber die Jahresberichte und Zeitschriften.

Möge man mir diese Mahnworte nicht iabel nehmen, ich wollte damit hauptsächlich für die Zukunft warnen vor den in den Muskelfasern nicht vorhandenen aber in sie hineingedichteten Fadennetzen, welche jetzt die verhängnissvolle Rolle in der Histologie der Muskeln weiter zu spielen drohen, welche frïher andern 
Trugbildern und Urtheilstäuschungen zufel, deren Ueberwindung eben nahe gerlickt zu sein schien.

Die Veröffentlichungen von Melland, van Gebuchten und Marshall verbreiten sich über diese Fadennetze.

Unsere Widerlegung der von diesen Autoren daruiber vorgebrachten Ansichten wird sich auf drei Punkte hauptsächlich concentriren. Erstens auf die Deutung, welche sie den Bildern vergoldeter Muskeln geben, zweitens auf das Bild, welehes sie von frischen Muskelfasern darstellen und endlich auf das Bild, welches sie den mit Härtemitteln behandelten Muskelfasern zuschreiben. Melland und Marshall, deren Abhandlungen in dem directen Zusammenhange der Fortsetzung der eineu durch die andere stehen, stiitzen ihre Beschreibung eines aus quer- und längslitufunden Faden zusammengesetzten, im Muskel vorhandenen Netzes vor\%ugsweise auf die Beobachtung vergoldeter Muskeln. Nur Melland befasst sich auch eingehender mit dem Bilde ganz frischer ohne Zusatz untersuchter und dem Bilde geliärteter Muskelfasern, $11 \mathrm{~m}$ die Ausdeutung der Goldbilder damit zu bewahrheiten. Darauf komme ich später zurück. Vorerst die Goldbilder. Was beide Autoren au diesen als Faden beschrciben sind nur Quer-oder Längsschnitte der Wände des Wabenwerkes, welches das Sarkoplasma um die Muskelsiulchen bildet und alle ibre Goldbilder sind so $z u$ deuten, wie wir die früher besprochenen Goldbilder (die in Fig. 1, 2, 3, 4, 5 u. 6 abgebildet sind) gedentet haben. Für die Muskeln zahlreicher Coleopteren findet sich meine Deutung der Goldbilder ïberdies ausfübrlich begriundet in den Untersuchungen (l. c. I. Theil pag. 110 u. d. f.).

Der Vergleich des in den Muskeln mittelst der Vergoldung dargestellten angeblichen Netzwerkes mit dem intracellulären Netzwerke niedriger stehender contractiler Gebilde (z. B. der Amoeben, Flimmerzellen etc.), welchen Vell and und Marshall anstellen, zerfällt damit in Nichts, und der von Melland ausgesprochene Satz: „that the striated muscular fibre really agrees fundamentally as regards histological structure with the other contractil tissue elements, in containing an intracellular network, differing from them merely in the greater amount of differentiation and more regular arrangement of the network" ist reine Schwärmerei.

Van Gehuchten siebt an den Goldbildern dieselben Fadennetze, wie Melland und Marshall sie sehen. 
Van Gehuchten's Abhandlung wirkt aber viel bestechender, als jene der englischen Autoren und zwar durch die Fülle des Materiales, welches van Gehuchten bearbeitet und durch die Mannigfaltigkeit der Methoden die er anwendet. Bei Geotrupes stercorarius, Astacus fluviatilis, Dyticus marginalis, Hydrophilus piceus und anderen Arthropoden (Hydrometra palustris, einer Fliege, Gryllotalpa vulgaris, Vanessa polychloros; Scorpio occitans, Tegenaria atrica; Lithobius und Geophilus; Dichelestium sturionis, Apus cancriformis) soll durch Beobachtung der frischen Muskeln, durch Behandeln derselben mit kochendem Wasser, mit Alkohol, mit Chromsäure und Ammoniumbichromat, mit verdünnter Salzsäure, Ameisensäure und Kalilange und durch Vergoldung sich die Richtigkeit einer zuerst von Car n oy im Jahre 1880 ausgesprochenen und in seiner "Biologie cellulaire" (1884 p. 193) niedergelegten Anschauung über den Muskelbau erweisen lassen. Sie wird durch folgende These ausgedrickt: „La cellule musculaire est une cellule ordinaire dont le réticulum s'est regularisé, et l'enchylème chargé de myosine." Das Reticulum plastinien und das Enchylème myosique sollen die zwei constituirenden Bestandtheile der quergestreiften Muskelfaser sein, welche wesentlich differente Eigenschaften besitzen und durch ibr verschiedenes Verhalten zu den angeführten Reagentien in verschiedener Erscheinungsweise demonstrirt werden können.

Carnoy und van Gehuchten bilden sich also taber die morphologische Bedeutung des angeblichen Netzwerkes eine ähnlich schwärmerische Vorstellung, wie Melland und Marshall und Macallum, den wil früher auch erwähnten, schliesst sich, indem er ein in den Muskelkernen seines Objectes beschriebenes Netz in das Netz der contractilen Substanz ubbergehen lässt, wieder der von ihm besonders hervorgehobenen Anschauung von Carnoy an. Van Gehuchten betont mit Recht, dass dem von ihm supponirten Reticulum im Muskel eine wesentlich andere Bedeutung zukomme, als den von Retzius beschriebenen Querfadennetzen. Diese hat Retzius als verzweigte und anastomosirende und in der Längenrichtung der Muskelfaser eigenthümlich mit einander verbundene Ausläufer von Zellen gedeutet.

In der That weicht die von Retziu s gegebene Beschreibung der Goldbilder der Muskelfasern himmelweit von jener Mell and's, Marshall's und van Gehuchten's ab. 
Mit der treuen Beschreibung der mikroskopischen Bilder vergoldeter Muskein von $R$ et $z$ i u s kann man sich vollständig im Einklang befinden, wenn man auch die von ihm gegebene morphologische Ausdeutung seiner Querfadennetze und einige daran geknüpfte Folgerungen nicht acceptirt (vergl. meine Untersuchung 1. c. I. Theil pag. 122).

Bei Melland, Marshall und van Gehuehten handelt es sich aber nicht bloss um eine bestreitbare morphologische Ausdeutung des richtig Gesehenen. Nein! Diese Autoren wurden vielmehr ganz vorzüglich durch falsch gesehene oder den realen Verbältnissen nicht entsprechend ausgelegte mikroskopisehe Bilder auf ihre Abwege geführt; davon werden wir uns des Weiteren ïberzeugen, wenn wir jetzt untersuchen, in welcher Weise van Gehuchten und Melland die Prïexistenz ihres Fadennetzes in der lebenden Muskelfaser darzathun suchen.

$\mathrm{Zu}$ diesem Zwecke muss ich zuerst in Erinnerung bringen was ich selbst durch das Studium ganz frischer noch lebender Muskelfasern festzustellen in der Lage war.

Ich habe in meinen Untersuchungen (1. c. Bd. LI pag. 53) mich viel mit den mikroskopischen Bilde ganz frisch, olne $\mathrm{Za}$ satz untersuchter Muskelfasern beschäftigt und als Resultat dieser Untersuchungen ausgesprochen, dass an den frischen Muskelfasern die früher scizzirten Einzelheiten der Muskelstructur grösstentheils gut erfasst werden können. Von den zablreichen Billern, welche ich am betreffenden Orte gegeben habe, reproducire ich hier zunächst zwei, um sie mit dem Bilde, welches $\nabla$ an Gehuchten und Melland von den frischen Muskelfasern geben zu vergleichen. Fig. $10 \mathrm{~A}$ stellt eine frische ruhende Muskelfaser von Geotrupes sylvaticus bei tiefer Einstellung des Mikroskopes dar. Fig. $10 \mathrm{~B}$ dieselbe Faser bei hober Einstellung.

In Fig. $10 \mathrm{~A}$ erscheinen die Streifen Z (Amici-Krausesche Querlinien, Engelmann's Zwischenscheiben, Ranvier's disques minces) am dunkelsten, viel weniger dunkel erscheinen die Streifen Q (Bowman's Scheiben, Engelmann's anisotrope Bänder), heller erscheinen die Streifen $J$ (isotrope Substanz von Engelmann, bandes claires von Ranvier); alle diese Streifen sind von einer deutlichen Längsstreifung durchzogen, die Längsstreifen erscheinen als sehr helle, alle Querstreifen durchsetzende Durchgänge und durch diese werden die Streifen $Z$ in nebenein- 
anderliegende Körner, die Streifen $Q$ in Stäbe, die Streifen $J$ in versehmälerte die Körner von $Z$ und die Stäbe von $Q$ verbindende Stï̀cke zerlegt. Die der Länge nach verbundenen Stäbe und Körner entsprechen den Maskelsäulehen, die hellen Durchgänge zwischen denselben dem Sarkoplasma.

Bei hoher Einstellung Fig. 10B kehrt sich dieLichtvertheilung um, die Sarkoplasmadurehgänge erscheinen dann am dunkelsten und entsprechend in anderen Helligkeiten dieGlieder der Muskelsäulchen. Ich habe darauf aufmerksam gemacht, dass dieser Wechsel der Lichtvertheilung bei beiden Einstellungen für die Muskelfasern von A m i ci eingehend besprochen wurde und dass er mit dem Vorhandensein verschieden lichtbrechender Substanzen im Muskel zusammenhängt ${ }^{1}$ ).

Alles stärker lichtbrechende erscheint an der Muskelfaser bei hober Einstellung heller, alles schwächer lichtbrechende dabei dunkel; dagegen alles stärker lichtbrechende bei tiefer Einstellung dunkel, alles schwächer lichtbrechende dabei hell.

An dem gewählten Beispiele sind keine Streifen N (Engel. mann's Nebenscheiben, Ranvicr's disques accessoires, Flögel's Kïrnerschichten) vorhanden. Wären sie vorhanden, so würden sie sich zu beiden Seiten von $Z$ in ähnlicher Weise wie dieser Streifen und vou dem letateren durch einen dem Streifen $J$ ähulichen Streifen E getrennt darstellen (Beispiele dafïr Untersuchung. 1. c. II. Theil, Tafel III, Fig. 18 u. 19).

Sehen wir nun wie dagegen van Gehuchten und Melland die frische Muskelfaser abbilden. Wir werden dabei auf äusserst merkwürdige Irrthümer stossen.

Fig. 11 gibt schematisch, auf die Grösse unserer Fig. 10 gebracht, in allen wesentlichen Theilen in Beaug auf welche Melland (siehe dessen Fig. 19 l. c.) und ran Gehuchten (siehe dessen Fig. 2, 38, 99, 111 und 126 in Etude sur la struct. intime etc. 1. c. und dessen Fig. 1 in anatom. Anzeig. 1. c.) tibereinstimmen, deren Bild des frischen Muskels wieder.

Ich habe an der Fig. 11 die Bezeichnung der einzelnen Streifen mit den von mir vorgeschlagenen Buchstaben angebracht. Beide Autoren stellen also die Streifen 7 dunkel und entsprechend den Muskelsiulchen in nebeneinanderliegende Körner getheilt dar, so wie sich die Streifen Z bei tiefer Einstellung darbieten (vergl. Fig. $10 \mathrm{~A}$ ).

1) Vergleiche Dippel, das Mikroskop, I. Theil p. 851 u. d. f. 2. Auf. Braunschweig 1883. 
In der Zeichnung von Melland sind diese Körner von $\mathrm{Z}$ der Länge nach, in den Zeichnungen von van Gehnchten dagegen der Quere nach durch dunkle Linien verbunden, das ist die wesentlichste Abweichung in den Zeichnungen beider Autoren.

Melland, welcher dem Wechsel der Lichtvertheilung beim Wechsel der Einstellung des Mikroskopes unter dem Titel: Transposition of the Bands, eine besondere Auseinandersetzung widmet, führt ganz entschieden an nnd bildet das auch in besonderen Figuren ab, dass bei tiefer Finstellung die Streifen $Z$ am dunkelsten erscheinen, dagegen die Streifen $J$ am hellsten, während die Streifen $\mathrm{Q}$ heller, als die $\mathrm{Z}$, aber dunkler, als die Streifen J erscheinen; dass dagegen bei hoher Einstellung die Streifen $Z$ am hellsten, die Streifen $J$ am dunkelsten, dagegen die $Q$ wieder in mittlerer Helligkeit erscheinen.

Kurz er behauptet nicht nur für die Streifen $Z$, sondern fur alle Streifen bei beiden Einstellungen ganz dasselbe, was ich auch als das Resultat meiner Untersuchungen angefiihrt habe.

Es ist mir darum schwer begreiflich, wie Melland bei tiefer Einstellung in die Streifen Q (Fig. 11) feine dunkle Linien einzeichnen konnte, welche die den einzelnen Muskelsäulchen entsprechenden dunklen Körner der Streifen Z der Länge nach verbinden. Solche dunkle Linien sind in den Streifen $Q$ bei tiefer Einstellung nicht zu sehen (vergl. Fig. $10 \mathrm{~A}$ ), sondern nur bei hoher Einstellung (vergl. Fig. 10 B), und bei dieser liegen sie dann nicht in der Verbindungslinie der Mittelpunkte der dann hell er scheinenden, den einzelnen Muskelsäulchen entsprechenden Körner der Streifen Z, sondern sie fallen zwischen dieselben (s. Fig. 10 B). Diese bei hoher Einstellnng dunkel erscheinenden Linien sind bei tiefer Einstellung hell und wie gesagt nichts anderes als Theile der optischen Längsschnitte des die gegliederten Muskelsäulchen trennenden Sarkoplasmas.

Das Bild welches van Gehachten gibt stimmt, wie schon hervorgehoben, mit dem ron Melland gezeichneten in Bezug auf die Lichtvertheilung überein.

Van Gehuchten fuihrt aber im Texte and in der Tafelerklärung ausdrücklich an, dass sein Bild der hohen Einstellung entspreche. Bei dieser Einstellung treten die Sarkoplasmadurchgänge in $Q$ in der That in Form von dunklen Linien auf, dagegen erscheinen aber dann die Körner von $Z$ nicht, wie van Gehuc hten 
sie zeichnet, dunkel, sondern wie ich und Melland übereinstimmend finden, hell; und wieder erscheinen die dunklen Linien in $Q$ nicht in der Verbindungslinie der Körner Z, sondern sie treffen zwischen dic Körner von $\mathrm{Z}$ (siehe Fig. $10 \mathrm{~B}$ ). Es haben also sowohl Melland, als auch van Gehuchten in dieselbe Darstellung der Muskelfaser Einzelheiten eingezeichnet, welche theilweise der tiefen, theilweise der hohen Einstellung entsprechen und noch überdies dieselben in linearer Richtung falsch auf einander bezogen.

Gerade diese Bilder sollen aber die Existenz des von Melland und von van Gehuehten angenommenen Netzes in den frischen Muskelfasern darthun. Die dunklen Linien in den Streifen Q Fig. 11 sollen die längslaufenden Fïden des Fadennetzes, die Körner von $Z$ sollen Theile dieses Fadennetzes sein und zwar die Knoten, in welchen die querlaufenden Fïden des Fadennetzes sich ansetzen und ebenso wie die Körner von $Z$ sollen auch die Körner von $\mathrm{N}$, wenn die letzteren Streifen vorhanden sind, Verlickungen der laingslanfenden Fäden des Fadennetzes sein. Nach Melland ist die zwischen den dunklen Linien im Streifen Q (Fig. 11) gelegene Substanz die Matrix, aus welcher sich beim Härten der Muskeln die sarcons elements bilden. Auch nach van Gehuchten existiren solche prismatische Elcmente im frischen Muskel nicht, sondern die Maschen des Fadennetzes sind erfüllt mit dem enchylème myosique und die hellen Streifen J, welche zwischen den Streifen $\mathrm{Q}$ und $\mathrm{Z}$ auttreten, bezeichnet er ohne weitere Begründung als cin optisches Phaenomen.

So meinen nun Melland und ran Gehuchten das Fadennetz am frischen Muskel demonstrirt zu haben und dieses selbe Fadennetz soll nun dureh die Vergoldung im imprägnirten, roth gefärbten Zustande in die Erscheinung treten. Faktisch sieht man dagegen am frischen Muskel nur die Muskelsäulchen mit den Gliedern $Q, J$ und $Z$ (Fig. $10 \mathrm{~A}$ ) eventuell noch den Gliedern E und $\mathrm{N}$ und zwischen den Muskelsäulchen die Sarkoplasmadurchgänge.

Ich behaupte und habe früher dargethan, dass sich bei der gewijhnlichen Vergoldung der Muskelfasern das Sarkoplasma färbt, die Muskelsäulchen dagegen nicht und dass die zierlichen Knotenreihen, welche man an den Goldbildern der Muskelfasern (vergleiche Fig. 6) sieht, davon herrühren, dass das Sarkoplasma zwischen den stark quellenden Gliedern $Q$ der Muskelsäulchen 
verdünnt, dagegen zwischen den weniger quellenden Gliedern $\mathrm{Z}$ der Muskelsäulchen zusammengedrängt und angesammelt erscheint. Die Knoten sind nur die optischen Querschnitte der Verdickungen der Wände des Wabenwerkes von Sarkoplasma, welches die Mnskelsüulchen in sich schliesst, und von dieser Verdickung, die anch in der Seitenansicht durch stärkere Absorption sich geltend macht, rührt auch die scheinbar durch Fäden bedingte Querverbindung der Knoten her (Fig. 6).

Melland und van Gehuchten identificiren dagegen die Knoten der Goldbilder mit den Gliedern Z der Muskelsäulchen, weil sie, wie wir geschen haben, fälschlich dic bei boher Linstellumg in den Streifen $\mathrm{Q}$ auftretenden dunklen Linien (Sarkoplasmadurchraiinge im optischen Längsschnitte) in die Verbindungslinie jener Glieder der Muskelsäulchen verlegen.

So wie die Goldbilder babe ich auch die Säurebilder einer ausfuihrlichen Analyse unterworfen (Untersuchungen I. Th. I. c. pag. 110) und gefunden, dass sich an mit Säure behandelten Muskelfasern die Muskelsüulchen und das Sarkoplasma in ganz ähnlicher Weise differenziren, wie bei der Vergoldung, und so wie meine Deutung der Goldbilder den Anschauungen, welche Melland, van Gehuchten und Marshall iber die Fadennetze vergoldeter Muskeln ausgesprochen haben widerstreitet, so widerstreitet auch meine Deutung der Säurebilder den mittelst Säuren von van Gehuchten dargestellten Fadennetzen. Mit verdiunter Kalilange, die van Gebuchten anch für die Darstellung der Netze besonders rühmt, finde ich aber wieder nur eine ganz ähnliche Differenzirung von Muskelsäulchen und Sarkoplasma, wie dieselbe an in Säuren gequollenen oder vergoldeten und dann in Säuren gequollenen Muskelfasern zu beobachten ist.

Ich habe jetzt noch die Bilder zu besprechen, welche Mell a n d und van Gehuchten den mit Härtemitteln behandelten Muskelfasern zuschreiben und an welchen sie wieder das Fadennetz demonstriren, welches sie an vergoldeten und an frischen Muskelfasern gefunden zu haben glauben.

Ich werde denselben wieder meine Anschaunng des Bildes gehärteter Muskelfasern entgegensetzen, welche ich in meinen Untersuchungen ausfïhrlicher dargelegt und begründet habe.

Es sollen mir hier die zwei schematischen Zeicbnungen Fig. 12 $\mathrm{R}$, und $\mathrm{R}$, dienen, diese Anschauung zu entwickeln. 
Fig. $12 \mathrm{R}$, stellt das Bild einer in Alkohol gehïrteten Muskelfaser bei tiefer Einstellung dar. Man sieht in derselben die Muskelsüulchen von einander getrennt durch helle Sarkoplasmadurchgängre. Die Muskelsäulchen erscheinen gegliedert. Die Glieder Z derselben, entsprechend dem Streifen Z, erscheinen am dunkelsten. Heller erscheinen die Glieder $Q$ derselben, entsprechend den Streifen Q, diese Glieder erscheinen an ihren Enden abgerundet, in ihrer Mitte verschmälert, also auf dem optischen Längsschnitte bisquitförmig. Ich habe diese Form der Glieder $Q$ für das Schema gewählt, weil sie sehr häufig zu beobachten ist und weil sie auch von Mell and so gezeichnet werden und auch van Gebuchten dieselben in vielen Fällen so beobachtet hat.

Diese Form ist aber nicht immer und ausschliesslich zu beobachten. Im Gegentheile es treten die verschiedensten Formen derselben an Weingeistpr:̈jparaten zu Tage. Sie küunen walzenstab- spindelförmig beobachtet werden, wic das sich auch aus der Darstellung von van Gehuchten ergiebt. Ich selbst habe solche verschiedene Bilder in den meinen Untersuchungen beigegebenen Tafeln in mahlreicher Menge dargestellt.

Fiir die Muskelfasern der Biene habe ich dureh rasehe Applikation von Alkohol auf frische, unter dem Miskroskope beobachtete Fasern gezeigt, wie sich deforminte Glieder $Q$ von der Art, wie sie in dic schematische Fig. $12 \mathrm{R}$, eingezeichnet wurden, aus den stabförmigen Gliedern $Q$ der frisehen Faser herstellen (vergl. Untersuch. 1. c. Bd. LI pag. 54 Taf. III Fig. 14 A, B, C, D).

Die Glieder $J$ der Muskelsäulchen (Fig. $12 \mathrm{R}$,) erscheinen am hellsten und etwas verschmälert.

Vergleichen wir mit dem beschriebenen Bilde der Muskelfaser bei tiefer Einstellung das Bild derselben Faser bei loher Einstellung ( Fig. $12 \mathrm{R}$, ), so sehen wir eine ähnliche Umkehr der Lichtvertheilung, wie wir sie beim Wechsel der Einstellung an den frischen Muskelfasern beschrieben haben. Die Sarkoplasmadurchgänge, welche ihrer Form nach das getrene Abbild der hellen Sarkoplasmadurchgänge des Muskels bei tiefer Einstellung sind, erscheinen am dunkelsten, die Glieder $Z$ der Muskelsäulchen am hellsten, weniger bell die Glieder Q, dunkler die Glieder J. Die in Form von mit Knoten besetzten Fäden erscheinenden Sarkoplasmadurehgänge stellen wieder nur die optischen Längsschnitte der Wände des Wabenwerkes von Sarkoplasma dar, welches die Muskelsäul- 
chen umschliesst. Durch Differenzirung der Muskelsäulehen, und des Sarkoplasmas gehärteter Muskeln mit Haematoxylin; durch Sericn von Querschnitten gehärteter Muskeln; und Vergleichung des Bildes, welches mit dem Messer angefertigte Querschnitte gehärteter Muskeln der verschiedensten Arthropoden ergeben, mit dem Bilde des Querschnittes vergoldeter oder mit Säure behandelter Muskeln glaube ich meine Anschaung liber das Bild gehärteter Muskelfasern in ausreichender Weise begründet zu haben. (Vergl. Untersuchungen 1. c. Bd. XLIX pag. 110, und Bd. LI p. 23).

Sehen wir dagegen wieder, wie Melland und van Geh uchten das Bild der gehürteten Faser darstellen. Die Fig. $12 \mathrm{M}$ giebt die Darstellnng von Melland wieder (vergl. dessen Diag. 8 und Fig. 21 l. e.). Die durch das Härtemittel geschrumpften und in ihrer Form veränlerten Elemente der Streifen $Q$ liegen lose in den Maschen eines Netzwerkes, dessen Knoten die Körner der Streifen Z sein sollen. Diese Körner, welche durch längs- und querlaufende Fiiden mit einander verbunden erscheinen, sollen alternirend mit den Elementen von $Q$ liegen, und zwischen je zwei der letzteren sollen die die Kürner von $Z$ der Länge nach verbindenden Fäden durchlaufen. Gegen diese Darstellung, wollen wir nur anfiüren, dass sie sich im Widerspruche befindet mit einer leicht an hunderten von Präparaten von in Alkohol conservirten Arthropodenmuskeln zu constatirenden Thatsache. Man findet an diesen immer die Körner der Streifen $Z$ genau in die Richtung der Lüngenaxe der in der Lüngenrichtung sich correspondirenden Stäbe von $Q$ fallen. wie das in Fig. $12 R$, dargestellt ist, und wie das von Amici bis hente alle Autoren, die sich mit diesem Gegenstande beschäftigten, behauptet haben.

$\mathrm{Zu}$ den letzteren gehört denn auch $\mathrm{van}$ Gehuchten, der von den gebärteten Muskelfasern zahlreiche Bilder (vergleiche seine Figuren 5, 6, 14, 15, 65, 70, 89, 91, 100, 102, 135 und viele andere) beschreibt, die was die Lage der Theile betrifft alle übereinstimmen mit der als Beispiel hier dargestellten schematischen Fig. $12 \mathrm{G}$. In dieser treten zunächst die längs- und querlaufenden Fäden des Fadennetzes hervor. Die Körner der Streifen $\mathrm{Z}$ sind die schon am frischen Muskel sichtbaren Knoten des „reticulum plastinien", wie das schon früher angefübrt worden ist. Während abcr am frischen Muskel die Maschen dieses Netzes ansgefüllt erscheinen mit dem Enchylème myosique, haben sich am gehärteten 
Muskel an die längslaufenden Fäden des Netzes besonders geformte Gerinnsel aus dem Enchylem ausgeschieden und angesetzt, die jetzt als Stäbe (bâtonnets) der Streifen $Q$ in die Erscheinung treten.

Man wird sich nun vor Allem fragen, warum diese Niederschläge aus dem Enchyleme, gerade die längslaufenden Fïden des Fadennetzes als Ansatzstellen in so regelmässiger Weise bevorzúgen sollen. Mir scheint dieser Versuch einer Erklärung der Stäbe von $Q$ ein äusserst geschraubter zu sein, und er hat, wie man siebt, das Voruandensein des Fadennetzes zur Voraussetzung, dessen Existenz wir schon widerlegt haben. Ich habe Bilder, wie sie Melland und van Gebuehten der gehärteten Muskelfaser zusehreiben, durchans niemals finden können. Ich balte sie für reine Phantasiegebilde und man kann hier nur wieder annehmen, dass wenigstens zum Theile die Verwechslung der hohen und tiefen Einstellung einiges Verschulden trifft.

Es ist endlich auch sehr leicht noch eine ganze Reibe von Eigenschaften, welche van Gehuch ten seinem "reticulum plastinien" und seinem „enchylìme myosique" zuschreibt, einfach abzuweisen. Das Reticulum soll durchans einfich brechend sein. Da aber nun die von anderen Autoren beschiriebenen Körner der Streifen $Z$ and der Streifen $N$ nach van Geluchten dem Netze angrehören und zwar die ersteren die optischen Querschnitte der Querfaden, die letateren Verdickungen (épaississements) der Läıgsfaden sein sollen, so kann van Gehuchten's Behauptung über die optischen Eigenschaften seines Reticulum nicht richtig sein. Man weiss seit Brüeke's Untersuchungen der Muskelfasern im polarisirten Lichte, dass die Körner oder Stäbe von $\mathrm{Z}$ und $\mathrm{N}$ (Zwischen- und Nebenscheiben; Brü cke's aus kürzeren sarcous elements gebildete, doppeltbrechende Streifen) anisotrop sind. Ich habe das bei sehr eingehenden und vielfachen Untersuchungen frischer, obne Zusatz im polarisirten Lichte untersuchter Muskelfasern immer nachweisen können. Sehen wir uns endlich das Enchylem an, welches nach van Gehuchten die Maschen des Fadennetzes im frischen Muskel erfiullen soll. Es soll eine hyaline, glanzlos und homogen erscheinende, mehr oder weniger flüssige oder teigige Substanz sein, welche, in Wasser gelöst, mineralische Salze und eine grosse Menge von Eiweisssubstanzen enthalten soll. Der Hauptbestandảtheil der Lösung soll das Myosin sein. Das „Enchylème myosique“ soll die doppeltbrechende Sub- 
stanz des frischen Muskels sein und diese Eigenschaft verdanke es dem Myosin, welches es enthält. Alles sebr schön! aber Alles nur Bchauptungen ohne Beweise.

Wenn jemand die Behauptung aufstellt, dass eine Eiweisslijsung die positiv einaxige Anisotropie der frischen Muskelfasern bedingt, so ist das jedesfalls eine Behauptung, die von vornherein nach unseren dermạligen physikalischen Kenntnissen nicht sofort verstïndlich erscheint. Im Gegentheile, derjenige der das behauptet, miisste es sich sehr angelegen sein lassen, uns auseinander zu setzen, wie er das eigentlich meint, und zu begründen vermag. Es kämen dabci alle die oft hervorgehobenen Schwierigkeiten in Betracht, auf welche schon die Auwendung des Begriffes Lösung anf die sogenannten unechten Lösungen der Eiweisslïrper stösst, und die clenso oft betonten Schwierigkeiten, welche die Definition des Aggregatzustandes organischer und organisirter Substanzen darbietet. Was das Myosin betrifft, so ist noch überdies zu bemerken, dass die Substanz, welche wir im geronnenen Muskel als Myosin bezeichnen, als solehe gar nicht im lebenden Muskel vorhanden ist, sondern sich walrsseheinlich dureh sehr complicirte Processe aus einer anderen Eiweisssubstanz oder durch das Zusammenwirken melirerer Substanzen bildet.

Ich komme also zu dem Resultate, dass ein Netzwerk im Sinne von Melland, Marshall und van Gehuchten und ein Fineliylem im Sinne des Letzteren in der quergestreiften Muskelfaser nicht existirt.

Die Annahme eines solchen Netzes beruht auf Irrthïmern in der Auslegung mikroskopischer Bilder und der Vernachlässigung bekannter Thatsachen der vergleichenden Morphologie der Muskeln.

Viele von den an die Existenz eines solchen Netzwerkes geknitpften Annahmen erscheinen gezwungen und einem einheitlichen und allgemeinen Verständnisse der bei verschiedenen Thieren auftretenden morphologischen Verschiedenheiten der Muskelfasern hinderlich, während durch meine im Eingange skizzirte Darstellung des Muskelbanes ein solches umfassendes Verständniss desselben vermittelt wird.

Die Bilder, welche die genannten Autoren auf Fadennetze im Muskel beziehen, kommen nur durch die besondere Inordnung des Sarkoplasmas im Muskel zu Stande, welches im Allgemcinen in Form eines Wabenwerkes die gegliederten Muskelsäulchen umgiebt. 
Ob das in solcher Weise angeordnete Sarkoplasma als solches noch eine feinere besondere Structur besitzt, die etwa mit der feinen netzartigen oder schwammigen Structur zu vergleichen wäre, welche man als "Zellstructur" am Protoplasma nachyuweisen versuchte, müssen erst noch weitere Untersuchungen lehren, was ich hier, um künftige Missverständnisse zu vermeiden, den fülschlich angenommenen Fadennetzen im Sinne Melland's, Marshall's und van Gehuchten's gegenüber noch besonders hervorheben will.

Zum Schlusse dieser kritischen Gänge möchte ich noch anführen, dass es mir beim Studium der umfangreichen Literatur der quergestreiften Muskelfasern immer den grössten Unmuth erregt hat, wenu ich gesehen habe, wie so oft alle Errungenschaften, welche wir Sehwann, Bowman, Briicke, Cohnheim, Köll iker, Engelmann u. A. in der Erkenntniss des Baues der quergestreiften Muskelfasern verdanken, leichteu Sinnes völlig über Bord geworfen wcrden, weil ich scbon lange die Ueberzeugung habe, dass in den von jenen Forschern aufgestellten Lehren vieles enthalten ist, was die directen Anknüpfungspunkte für einen erfolorreichen Anshau der Histologie der quergestreiften Muskelfasern darbietet.

Die Richtigkeit dieser Anschaunng hat sich mir auch völlig bewährt bei den schon öfter eitirten Untersuchungen (Bd. XLIX und LI 1. c.), in welchen ich auf breitester vergleichend histologischer Grundlage Schritt für Schritt eine Analyse des Muskelbaues zu geben versuchte. Ich muss mir erlauben, auch dieses Ergebniss meiner Arbeiten hier besonders hervorzuheben.

Ich glaube darum auch, dass wir für den Bau der Muskelfasern, trotz aller offenen Fragen doch eine Reihe erkannter Thatsachen als so fest begründet ansehen miissen, dass wir an diesen nicht immer wieder rütteln lassen dürfen, sondern uns vielmehr immer zuerst fragen müssen, wie neue, wirklich reelle Funde mit denselben in Einklang gebracht werden können. Es handelt sich ja doch auch in der Histologie der Muskeln um stetige Fortentwicklung der Wissenschaft durch streng methodische Forschung, nicht aber um dichterische Conceptionen, dargestellt im Gewande wissenschaftlicher Abhandlungen. Sonst wird die Muskelhistologie niemals den wankenden Boden verlassen, auf welchem sie sich, wie ich überzeugt bin, unnöthig lange Zeit und nicht zum Ansehen der histologischen Wissenschaft bewegt hat. 
Als ich die vorliegende Abhandlung eben abgeschlossen hatte, kam mir eine Abhandlung ïber die Muskeln von Ramón y Cajal $\left.{ }^{1}\right) \mathrm{zu}$.

Dieselbe ist befruchtet von den Lebren Carnoy's, Melland's und van Gehuchten's.

Auch Ramon y Cajal will in der Muskelfaser Fadennetze, und zwar den Krause'schen Streifen entsprechende Querfadennetze, welehe durch Längsfäden verbunden sein sollen, nachweisen.

Die Maschen der Querfadennetze stellt er sich durch Membranen verschlossen vor. Als besondere Stiutze der letzteren Anschannng führt or an, dass oft in Mitte einer Masche frei und obne Zusammeuhang wit dem Netze Ansammlungen einer Substanz anftreten, die sich den Faden des Netzes völlig gleich verhält. Diese Ansammlungen seien aber nur als von der in der Masche ausgespannten Membran getragene Knotten zu deuten.

Ich habe aber schon vor längerer Zeit namentlich für die Muskeln der Hydrophiliden (Hydrophilus piceus, Hydrocharis caraboides) ausfuilurlich dargethan und nach versehiedenen Methoden begriundet (Untersucb. Bd. XLIX 1. c. jag. 125 und Bd. LI l. c. pas. 29, dass die, wie die Balkeu des die Co hn he i m'sehen Felder des Querschnittes umgebenden Netzes aussehenden, mittelständigen Punkte der Cohnheim'schen Felder nur die Querschnitte von

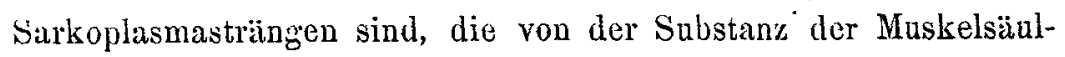
chen umfasst werden. Es ist mir nicht bekannt geworden, dass irgend jemand diese meine Anschauung Schritt für Schritt, so wie ich sie zu begriunden snchte, widerlegt hätte. Ich halte sie darum auch den gewagten Deutungen von Ramon y Cajal gegenüber aufrecht. Die Längsfaden stiitzt Ramon y Cajal ebenso wie Melland und van Gehuchten anf missdentete dunkle Linien in den Streifen $Q$ der frischen Muskeln. Zur Darstellung der Netze bedient er sich wie Melland und van Gehuchten der Vergoldung und der Anwendung von verdünnten Säuren und Alkalien.

In Bezug auf die Stäbe von $Q$ in den gebärteten Muskeln

1) Ouservations sur la texture des fibres musculaires des pattes et des ailes des insectes. Internat. Monatssch. für Anatomie u. Physiologie, Bd. V p. 205 . 
(bâtonnets de myosine) schliesst sich Ramon y Cajal der durch die Figur $12 \mathrm{M}$ illustrirten Ansicht von Melland an, dass sie zwischen den längslaufenden Fäden des Netzwerkes (fibrilles preexistantes von Ramon y Cajal, bars of the network von Melland) liegen, und bestreitet die von van Gehuchten behauptete Lage der Stäbe (bâtonnets) Fig. 12 G.

Wir haben aber fruher angefuhrt, dass die Behauptung von Melland über die Lage der Stäbe von $Q$ im Widerspruch stehe mit leicht und klar zu constatirenden Thatsachen und mit den Angaben aller anderen Histologen. Dasselbe gilt also auch ron der Behauptung Ramon y Cajal's, während van Gehuchten, abgesehen von seiner Deutung der Stäbe (bâtonnets), wenigstens ibre Lage richtig angiebt.

Ich glaube uber Ram on y Cajal's Arbeit genug gesagt zu haben, um sie ebenso wie jene von Melland und van Gehuchten als nicht beweisend fiur die Existenz des supponirten Fadennetzes hinzustellen. Ueber die von Ramon y Cajal behandelten Flugmuskeln der Insekten enthalte ich mich vorläufig jeder Kritik, so wie ich das fruher, was ich nun auch ausdruicklich anführen will, auch beztiglich der Mittheilungen van Gehuchten's über die Flugmuskeln gethan habe. Ich habe schon zu wiederholten Malen die Flugmuskeln der Insekten als eine histologisehe Specialität bezeichnet, die ihrer besonderen Bearbeitung bedarf.

\section{Tafel-Erklärung.}

Tafel VII.

Fig. 1. Querschnitte vergoldeter Flossenmuskelfasern vom Seejferdchen.

Fig. 2. Querschnitt einer vergoldeten Flossenmuskelfaser vom Seepferdchen (sehr stark vergrössert).

Fig. 3. Querschnitt einer vergoldeten Muskelfaser von Musca vomitoria.

Tafel VIII.

Fig. 4. Stück eines Querschnittes einer vergoldeten Muskelfaser von Maja squinado.

Fig. 5. Querschnitt einer vergoldeten Muskelfaser eines gewöhnlichen Stammmuskels des Seepferdchens.

Fig. 6. Längenansicht einer vergoldeten Flossenmuskelfaser vom Seepferdchen (sehr stark vergrössert wie Fig. 2).

Fig. 7. Querschnitte von in Alkohol gehärteten und mit Hämatoxylin gefärbten Flossenmuskelfasern des Seepferdchens. 
Fig. 8. Querschnitt einer in Alkohol gehärteten und mit Hämatoxylin gefärbten Muskelfaser von Musca vomitoria.

Fig. 9. Querschnitt einer mit Osmiumsäure behandeiten Flossenmuskelfaser vom Seepferdchen. Die Figuren 1, 3, 4, 5, 7, 8 und 9 bei derselben Vergrösserung gezeichnet.

Fig. 10. Lebende Muskelfaser von Geotrupes sylvaticus. A bei tiefer, B bei hoher Einstellung des Mikroskopes.

Fig. 11. Bild einer lebenden Insectenmuskelfaser nach Melland und $v$ an Gehuchten.

Fig. 12. Bilder gehärteter Muskelfasern von Insecten. $R$, bei tiefer, $R_{, \prime}$ bei hoher Einstellung, M. nach Melland, G. nach van Gehuchten.

\section{Die Verknöcherung des Unterkiefers und die Metaplasiefrage.}

Ein Beitrag zur Lehre von der Osteogenese.

$$
\text { Von }
$$

\section{Dr. Josef Schaffer,}

Assistent am Institute für Histologie und Embryologie in Graz.

Hierzu Tafel IX-XII.

\section{Inhalt.}

I. Einleitung.

II. Allgemeines und Historisches über Metaplasie.

III. Der Unterkiefer.

IV. Material. Untersuchungsmethode.

V. Erste Anlage des Gelenk- und Kronenfortsatzes. - Knochenbildungsgewebe (osteogenes Blastem).

VI. Die Knorpelkerne.
A. Erstes Auftreten. B. Weitere Entwicklung.

VII. Die Ossificationsvorgänge an den Knorpelkernen.

1. Verknöcherung des Kronenfortsatzes.

2. Verknöcherung des Gelenkfortsatzes.

A. Ossificationsvorgänge bis zur Entwicklung einer Ossificationslinie. - Perichondraler Typus (Typus der Auflagernng).

B. Weitere Ossification. - Modificirt endochondraler Typus (Typus der Einlagerung).

VIII. Schluss und Zusammenfassung.

Erklärung der Abbildungen. 